\title{
Uma visão antropológica do prodigioso jejum de mulheres ocidentais*
}

\author{
Carole M. Counihan ${ }^{* *}$
}

\section{Resumo}

No prodigioso jejum, às vezes até a morte, mulheres ocidentais expressaram uma relação específica com a comida durante quase oito séculos. Este ensaio tenta explicar esse comportamento entretecendo os finos e fascinantes dados históricos apresentados nos três livros resenhados - Holy Anorexia (Bell, 1985); Fasting Girls: The Emergence of Anorexia Nervosa as a Modern Disease (BRUMBERG, 1988) e Holy Feast and Holy Fast: The Religious Significance of Food to Medieval Women (BYNUM, 1987) - vendo-os a partir de perspectivas interculturais e totalizantes fundamentais para a antropologia. Pretendo mostrar que o jejum de mulheres ocidentais difere radicalmente de outros tipos de jejum observados por antropólogos ao redor do globo e que envolve uma alteração altamente simbólica da relação universal das mulheres com a comida. Argumento que ela pode ser mais bem compreendida como um comportamento pluri-determinado, uma combinação de fatores ideológicos, econômicos, políticos e sociais.

Palavras-chave: Jejum, Antropologia, Alimento, Mulheres, Comida.

\footnotetext{
"Counihan, Carole M. An Anthropological View of Western Women's Prodigious Fasting. A review essay. In: Counihan, Carole M. The Anthropology of Food and Body: Gender, Meaning and Power. New York/London, Routledge, 1999, pp. 93-112. [Tradução: Plínio Dentzien]. O comitê editorial do cadernos pagu agradece as autorizações da autora e da editora para publicar este capítulo de livro. Esta é uma versão ligeiramente revisada de um artigo originalmente publicado em Food and Foodways,1989. Eu agradeço a Steve Kaplan, Pamela Quaggiotto, e especialmente Jim Taggart, quem leu tantas versões que nenhum de nós consegue lembrar.

** Professora de Antropologia da Universidade de Millersville. carole.counihan@millersville.edu
}

cadernos pagu (39), julho-dezembro de 2012:15-53. 
Uma visão antropológica do prodigioso jejum de mulheres ocidentais

An Anthropological View of Western Women's Prodigious Fasting

\begin{abstract}
In prodigious fasting, sometimes to death, Western women have expressed an extraordinary relationship to food for almost eight centuries. This essay attempts to explain such behavior by weaving together the fine-grained and fascinating historical data presented in the three books under review - Holy Anorexia (BELL, 1985); Fasting Girls: The Emergence of Anorexia Nervosa as a Modern Disease (BRUMBERG, 1988) e Holy Feast and Holy Fast: The Religious Significance of Food to Medieval Women (BYNUM, 1987) - and viewing them from the cross-cultural and holistic perspectives fundamental to anthropology. I aim to show that Western female fasting differs radically from other kinds of fasting observed by anthropologists across the globe and that it involves a highly symbolic alteration of women's universal relationship to food. I argue that it is best understood as a multidetermined behavior, an interplay of ideological, economic, political, and social factors.
\end{abstract}

Key Words: Fasting, Anthropology, Women, Food. 


\section{Um Ensaio Bibliográfico}

Bell, Rudolph M. Holy Anorexia. Epílogo de William N. Davis. Chicago, University of Chicago Press, 1985.

BRUMBERG, Joan Jacobs. Fasting Girls: The Emergence of Anorexia Nervosa as a Modern Disease. Cambridge, Harvard University Press, 1988.

BYNUM, Caroline Walker. Holy Feast and Holy Fast: The Religious Significance of Food to Medieval Women. Berkeley, University of California Press, 1987.

No prodigioso jejum, às vezes até a morte, mulheres ocidentais expressaram uma relação específica com a comida durante quase oito séculos. Este ensaio tenta explicar esse comportamento entretecendo os finos $e$ fascinantes dados históricos apresentados nos três livros resenhados, vendo-os a partir de perspectivas interculturais $e$ totalizantes fundamentais para a antropologia. Pretendo mostrar que o jejum de mulheres ocidentais difere radicalmente de outros tipos de jejum observados por antropólogos ao redor do globo e que envolve uma alteração altamente simbólica da relação universal das mulheres com a comida. Argumento que ela pode ser mais bem compreendida como um comportamento pluri-determinado, uma combinação de fatores ideológicos, econômicos, políticos e sociais. Embora a cultura ocidental tenha mudado muito ao longo dos oito séculos em que mulheres recusaram comida, persistem certas forças, fazendo do jejum radical uma afirmação significativa. Essas forças incluem a identificação das mulheres com a comida, uma ideologia judeu-cristã dualista e absolutista, uma estrutura econômica e política patriarcal e uma organização familiar que limita a autonomia e potencial femininos.

Os três livros resenhados oferecem dados e interpretações complementares que, em seu conjunto, iluminam o enigma das mulheres que jejuam. Rudolph Bell contribui com uma abordagem 
Uma visão antropológica do prodigioso jejum de mulheres ocidentais

psicanalítica e material aprofundado de casos sobre várias mulheres santas italianas que, entre o ano de 1200 a. D. e o presente, praticaram jejum extremo. Onde há fontes, ele enfoca a vida familiar das santas, as experiências de infância e amamentação e a evidência da fixação oral das mulheres. Sua iluminação da psicologia individual e das experiências familiares das santas anoréxicas fornece parte essencial da explicação de por que as mulheres jejuam.

Caroline Walker Bynum usa uma aproximação "funcionalista e fenomenológica" para analisar as dimensões simbólicas e culturais do jejum (6). Ela tenta "mostrar os múltiplos significados da comida e sua penetração no simbolismo religioso" das mulheres medievais (5). Embora discuta as descrições hagiográficas de seus objetos, presta atenção específica às palavras das próprias santas, convencida de que revelam a riqueza $e$ complexidade do jejum, da devoção eucarística, dos milagres da comida e de sua doação e das emissões corporais milagrosas centrais à expressão religiosa das santas medievais. Seu livro é ricamente documentado com as declarações poéticas, eróticas e simbólicas das santas sobre a união com Deus através da comida e do jejum. Faz uma contribuição crucial à interpretação de seu comportamento e nos permite examinar o papel da ideologia ao longo do tempo como um contexto significativo do jejum.

O livro de Joan Jacobs Brumberg tem a visada histórica e explicativa mais ampla na medida em que ela se dispõe a explicar "o surgimento da anorexia nervosa como doença moderna" considerando mudanças no jejum feminino e respostas a ele desde a idade média até o presente. Ela utiliza rico material de fontes primárias de revistas médicas, de jornais e registros não publicados de casos sobre as "miraculosas donzelas que jejuam" dos séculos dezesseis e dezessete, sobre as "meninas que jejuam", do dezoito, e especialmente sobre as anoréxicas, do dezenove. Brumberg se concentra em como a anorexia perdeu sua dimensão espiritual principal e ficou, na era vitoriana, firmemente estabelecida como doença. Ela mostra como "o amor e o trabalho 
na família burguesa" (126) estimulavam adolescentes do século dezenove a recusar comida, e documenta como o jejum feminino de hoje se relaciona a crenças sobre magreza e perfeição, à posição subordinada da mulher na sociedade $e$ a relações familiares. Advoga um modelo multi-causal que considera a anorexia nervosa um "vício em passar fome", disparado $e$ sustentado por fatores biológicos, psicológicos e culturais. ${ }^{1}$

\section{Antropologia: totalizante e comparativa}

Um conceito totalizante de cultura é central para o método e a interpretação antropológicos. Citando o venerável Edward Tylor (1958:1), a cultura "é aquele complexo todo que inclui conhecimento, crença e moral, lei, costume e quaisquer outras capacidades e hábitos adquiridos pelo homem como membro da sociedade." Os antropólogos acreditam que qualquer artefato cultural, seja ele objeto, comportamento, símbolo ou pensamento,

${ }^{1} \mathrm{O}$ conhecimento atual sugere que a disfunção biológica não parece ser a causa da anorexia santa nem da moderna (Bell, 1995:14-15; Brumberg, 1988:24-27; Bruch, 1973, cap. 3). Embora sintomas biológicos ocorram em jejuadoras medievais e modernas - inclusive percepção distorcida, sensibilidade ao frio e à luz, constipação, metabolismo mais lento, desequilíbrio hormonal e amenorreia (Bruch, 1973; Bynum, 1987; Bell, 1985) - eles parecem ser mais efeitos do que causas. Em estudos de inanição ou quase inanição, nem antropólogos (Holmberg, 1969; Turnbull, 1972), nem aqueles que pesquisaram vítimas de guerra ou de campos de concentração (Bruch, 1973, cap. 2; Winnick, 1979) observaram que a falta de comida por si só causasse anorexia nervosa. Bell observa sobre as pessoas na idade média: "A fome por si só certamente não causou a anorexia santa" (14). Além disso, a alimentação não cura o distúrbio; anoréxicas alimentadas à força em geral começam a jejuar tão logo possam (Bruch, 1978, cap. 6; Lawrence, 1984, cap. 5), enquanto que as vítimas "normais" da inanição agradecem pela comida (Firth, 1959; Winnick, 1979). Entretanto, algumas pessoas parecem suscetíveis ao que Brumberg chama de "vício da inanição" (1988:31); algumas pessoas - e não há razão por que elas apenas existam em sociedades ocidentais - parecem ter uma predisposição biológica. Mas não se tornarão jejuadoras santas ou anoréxicas, a menos que forças tanto psicológicas quanto culturais façam da negação da comida uma afirmação poderosa. 
Uma visão antropológica do prodigioso jejum de mulheres ocidentais

deve ser sempre visto como produto de um ser humano biológico, psicológico e social, e explicado como parte de um sistema cultural total que consiste de economia, organização política, estrutura social e ideologia. Esses componentes, separados por simplicidade analítica, são encapsulados como bonecas russas. Uma crença fundamental da antropologia é a unidade funcional dos sistemas culturais (ver, p. ex., Geertz, 1973; Wolf, 1974; Peacock, 1986).

Uma explicação antropológica do jejum de mulheres ocidentais começa, então, com a suposição de que o jejum é uma peça no mosaico cultural, uma peça extraordinária, mas que se encaixa. $^{2}$ Só pode ser entendida em relação com o resto do quadro cultural que inclui produção, distribuição, consumo, estruturas de poder de controle e alocação de recursos, estrutura de decisões públicas, organização familiar, padrões de casamento $e$ de criação de filhos, e sistemas de crenças, especialmente porque estes se manifestam através dos modos de alimentação (ver, p. ex., Richards, 1939; Kahn, 1986).

A abordagem intercultural, fundamental para a epistemologia antropológica, também pode contribuir para a compreensão do extraordinário jejum de mulheres desde a idade média até o presente na Europa e na América do Norte. Ela nos permite saber quão comum ou incomum é esse comportamento no mundo e examinar as condições que estimulam ou impedem o jejum extremo. A visão comparativa nos permite ver os traços comuns na diversidade do jejum feminino e suas radicais diferenças dos modos como as mulheres de culturas não ocidentais se relacionam com a comida.

\section{O Dom e sua Recusa}

A recusa ao alimento, argumento, é uma afirmação significativa em todas as culturas e significa a negação de relação.

2 Geertz (1973:43) afirma que "Talvez esteja nas particularidades das pessoas suas idiossincrasias - algumas das mais instrutivas revelações sobre o que pode, genericamente, ser considerado humano". 
Em seu clássico estudo sobre O Dom, Marcel Mauss (1967) mostrou como a cultura é um sistema de unidade funcional onde a troca desempenha um papel fundamental na ligação entre as pessoas, mantendo a paz e afirmando crenças. ${ }^{3}$ Argumenta que presentes são parte de certo número de "fenômenos sociais totais." Neles, todos os tipos de instituições - religiosas, legais, morais e econômicas - encontram expressão simultânea. O dom envolve uma tríplice obrigação: dar, receber e reciprocar. A recusa em dar ou receber é um insulto que rompe as relações. A recusa em reciprocar significa incapacidade de fazê-lo e vergonha. Dar aos outros é a base do poder, pois quem recebe deve a quem dá. Mauss considera todos os tipos de dar e receber, mas muitos de seus exemplos envolvem doações de comida, que são fundamentais entre culturas primitivas e importantes em todas as sociedades. Marshall Sahlins (1972) sublinha as pressões particularmente fortes em grupos sociais pelo compartilhamento $e$ seu poder de determinar a sociabilidade:

A comida dá vida, é urgente e geralmente simbólica do lar e da casa, se não da mãe: comparada com outras coisas, a comida é mais prontamente, ou mais necessariamente compartilhada... Negociações com comida são um delicado barômetro, como se fosse uma afirmação ritual, das relações sociais, e a comida é assim empregada instrumentalmente como um mecanismo que dá início, sustenta ou destrói a sociabilidade... Comida oferecida de modo geral, notadamente como hospitalidade, significa boas relações... Comida não oferecida na ocasião apropriada ou não aceita significa más relações... Nesses princípios de troca instrumental de comida parece haver pouca variação entre os povos (id.ib.:215-16).

Grupos tão diversos como os bosquímanos caçadores $e$ coletores do sul da África (Lee, 1979, 1984; Marshall, 1976; Shostak,

3 A importância da troca é tão fundamental para a antropologia, que passa a ser axiomática. Veja, por exemplo, Lévi-Strauss 1967; Malinowski 1922; and Weiner 1988. 
Uma visão antropológica do prodigioso jejum de mulheres ocidentais

1981; Thomas, 1959), os sharanahua da Amazônia peruana (Siskind, 1973) e os sardenhos rurais (Counihan, 1981) fazem do compartilhamento da comida a definição da relação. O comensalismo - o compartilhamento da comida - estabelece comunhão e conexão em todas as culturas. A autonegação da comida e a recusa a comer com os outros representam uma severa ruptura da conexão. Embora os três autores difiram na semelhança que atribuem ao jejum feminino ao longo do tempo, $e$ Bynum esteja certa em que os significados específicos da comida derivam das culturas e variam entre elas (206), dados etnográficos sugerem que no nível mais geral a recusa ao alimento significa ruptura de conexão e esse significado se expressa nas mulheres que jejuam.

\section{Mulheres e Comida}

Os dados etnográficos sugerem outro universal da relevância para a anorexia sagrada e a moderna: a ligação profunda entre mulheres e comida. A comida é um cuidado particularmente importante e um símbolo para as mulheres em todas as culturas. As mulheres têm responsabilidade universal na preparação $e$ consumo dos alimentos (D'Andrade, 1974), e em muitas culturas também em sua produção e distribuição (ver, p. ex., Lee, 1979). Elas são definidas como criadoras e desempenham esse papel principalmente através da alimentação. Além disso, as próprias mulheres se tornam alimento para seus filhos durante a gravidez $e$ a lactação, intensificando sua identificação com a comida e sua relevância como símbolo. Em muitas culturas, como entre os antigos e modernos astecas no México (Taggart, 1983), as mulheres são associadas à fertilidade da terra e seu alimento abundante.

As mulheres ocidentais também usam a comida como símbolo do eu, mas as jejuadoras baseiam sua identificação com a comida na negação e na obsessão. A maioria dos que jejuaram ao longo da história ocidental foi de mulheres. Embora homens também jejuassem na Idade Média, Bynum (cap. 3) deixa claro 
que eles não o fizeram com a prevalência nem com o rigor das mulheres que "usaram o pão, o sangue, a fome e a comida como imagens dominantes da união com Deus e com o vizinho" (93). Como observa Brumberg, durante os séculos dezessete, dezoito e dezenove, os que se abstinham de comida incessante e totalmente eram "donzelas milagrosas" (49) e "meninas em jejum" (cap. 3); "não havia, de fato, meninos que jejuavam" (99). Só raramente homens praticaram o jejum extremo, e o fizeram apenas para demonstrar algo específico, como o médico eclético Henry S. Tanner, que alugou Clarendon Hill em Nova York e jejuou por quarenta dias para mostrar que isso era possível (89-90). Hoje, a maioria dos pesquisadores estima que nove de cada dez anoréxicos são mulheres e concluem que a desordem é feminina, sofrida por alguns homens que compartilham certos aspectos da experiência feminina (Lawrence, 1984:13).

A obsessão caracteriza a identificação das jejuadoras com a comida ao longo da história ocidental. Por exemplo, dizem amigos da santa medieval Colomba da Rieti (nascida em 1497):

\begin{abstract}
nunca a vimos provar pão, ou peixe, ou ovos, ou queijo, ou qualquer coisa semelhante, nem qualquer outra comida, exceto que algumas noites ela provava algum pedaço de fruta, lambendo-a para obter o suco, e bebia água... às vezes sorvia um pouco da sopa de grão de bico que sobrava nos pratos das freiras ou chupava (mas não comia) sobras de folhas de salada... Ela o fazia para punir seus sentidos porque a comida tinha estragado e estava coberta de moscas (citado em Bell, 156).
\end{abstract}

Outras santas medievais tinham sonhos torturantes cheios de tentações de comida, usavam imagens de comida como Deus e Deus como comida, e tinham uma relação de êxtase com a eucaristia. Embora nos faltem dados nos pensamentos e sensações relativas à comida das meninas que jejuavam nos séculos dezessete, dezoito e dezenove (Brumberg, 165), Colomba prefigura as anoréxicas modernas incessantemente preocupadas com 
Uma visão antropológica do prodigioso jejum de mulheres ocidentais

comida. Como diz Aimee Liu em sua narrativa autobiográfica da anorexia nervosa,

Comida. Esse é o açoite. Não posso escapar. Se não como, sinto falta, mas penso constantemente no que estou perdendo. Se como, me condeno, e conto sem cessar o que lamento comer. Mas o que é verdadeiramente imperdoável é a maneira como isso me cega para o resto da vida (1979:153-54).

Algumas anoréxicas encenam rituais secretos com a comida, como mastigar cada bocado cem vezes (Leverkron, 1978). Outras enfocam completamente um bocado, como a paciente Tania, de Hilde Bruch (1978, 91), que "comia um mínimo docinho M \& M muito lentamente, beliscando-o e dizendo a si mesma que podia sentir que seu estômago se enchia".

Do século treze ao presente, a comida forneceu um canal importante para a auto-expressão das mulheres, ainda que os significados variem. As mulheres medievais, nos diz Bynum, eram culturalmente definidas como criadoras (277) e encontravam uma fonte de santidade em ver-se como comida, pois se identificavam com Cristo, que se torna comida na Missa para redimir a humanidade. Sua própria capacidade de amamentar ia ao lado de sua associação com "os seios de Maria com a alimentação eucarística da alma" (271). Na era vitoriana, as burguesas usavam a preparação elaborada da comida e seu consumo como símbolo de sua posição social e do amor que ofereciam a suas famílias (Brumberg, cap. 5). As mulheres modernas, particularmente aquelas com anorexia nervosa, fazem da comida e de sua negação em busca da extrema magreza o foco principal de sua identidade, "análogo importante do eu" (id.:260).

Há importantes diferenças no que a comida significou para as mulheres em diferentes períodos históricos, diferenças que acompanham a secularização mencionada tanto por Bell (170-77) quanto por Brumberg (passim) e refletem as atitudes radicalmente 
distintas em relação à vida e à natureza, mencionada por Bynum (300). Mulheres modernas procuram o domínio sobre seus corpos para alcançar a perfeição pela magreza; mulheres medievais procuravam a transcendência de seus corpos para atingir a santidade pelo ascetismo; mulheres vitorianas buscavam uma feminilidade sublime e delicada pela negação das necessidades corporais. $\mathrm{O}$ que todos esses significados têm em comum é a negação: do corpo, da natureza física feminina e, em casos extremos, da própria vida.

As santas medievais faziam da comida o principal veículo em sua busca pela piedade. Assim interpreta Bynum seu comportamento:

as mulheres jejuam - $e$ a fome se torna uma imagem do excruciante e nunca saciado amor por Deus. As mulheres alimentam - e seus corpos se tornam uma imagem do sofrimento derramado pelos outros. As mulheres comem e seja a sujeira de corpos enfermos ou a carne e o sangue da Eucaristia, as comidas são o sofrimento $e$ a humanidade de Cristo, com os quais é preciso estar antes de chegar ao triunfo, à glória ou à divindade (186).

Seus extraordinários comportamentos incluíam não só o jejum - chamado de anorexia sagrada ou admirável [mirabilis] mas também, como ressalta Bynum, um conjunto de outras atividades centradas na comida (93, capítulos 4 e 5 , e passim). As santas medievais curavam os enfermos com óleo ou leite que fluíam de seus corpos, antes ou depois da morte. Algumas multiplicavam comida em milagres, emulando o milagre dos pães $e$ peixes de Cristo. Muitas davam a comida aos pobres, muitas vezes contra os desejos de seus pais ou maridos. Algumas mascavam e cuspiam a comida ou vomitavam refeições que eram forçadas a consumir, como as bulímicas de hoje (Boskind-White e White, 1983; Cauwels, 1983; Striegel-Moore, Silberstein e Rodin, 1986). Outras santas jejuadoras comiam apenas a Hóstia, tinham visões da Eucaristia, sentiam a Hóstia como inebriante ou doce, e 
Uma visão antropológica do prodigioso jejum de mulheres ocidentais

supostamente podiam distinguir a consagrada da não consagrada, vomitando esta última. Algumas - como Santa Verônica (Bell:7677), Catarina de Sienna (Bynum:172; Bell:25), Catarina de Gênova (Bynum:82) e Angela da Foligno (Bell:108) - comiam sujeira como sacrifício e auto-negação, consumindo pus, cascas de feridas, piolhos, lavagem de leprosos, comida ruim ou estragada, vômito de gato, insetos, vermes e aranhas. Muitas de suas ações envolviam distorções da relação usual das mulheres com a comida: davam seus eflúvios não como substância física para suas crianças, mas como nutrição espiritual para os pobres; não incorporavam a comida, mas a vomitavam; não comiam alimentos, mas seu oposto - sujeira ou espírito.

As modernas anoréxicas também têm uma relação distorcida com a comida; não perseguem a santidade, porém, mas a magreza e o autocontrole através da negação da comida (Brush, 1978:xi). ${ }^{4}$ Meninas anoréxicas sentem grande orgulho de seu desgaste e sofrem de uma imagem corporal severamente distorcida. Não conseguem ver sua própria decadência e se sentem continuamente gordas mesmo quando estão à morte por inanição. Elas perdem mais de $25 \%$ do peso corporal e outros efeitos relativos à inanição. Estão obcecadas com comida e com seus corpos; devotam-se fanaticamente a dietas e exercícios; e, como suas semelhantes medievais, convencem a si mesmas de que a fome é agradável e valiosa (Brush 1973, 1978). As anoréxicas modernas não procuram ordinariamente a transcendência religiosa e a união com Deus pelo jejum, embora muitas relatem

\footnotetext{
${ }^{4}$ Há uma vasta literatura sobre Anorexia Nervosa, a qual está bem recoberta no livro de Brumberg, especialmente no primeiro capítulo e em suas notas. Abordagens feministas sobre transtornos alimentares foram apresentadas no capítulo 5 deste volume. Alguns títulos importantes são Bruch 1973, 1978, 1988; Bordo 1993, Boskind-Lodahl 1976; Boskind White 1983; Cauwels 1983, Chernin 1981, 1985; Dally 1969; Garfinkel and Garner 1982; Gordon 1988; Lawrence 1984; Levenkron 1982; Macleod 1981; Orbach 1978, 1982; Palazzoli 1974; Striegel- Moore, Silberstyein, and Rodin 1986; and Thompson 1994.
} 
que a experiência faz com que se sintam limpas, puras e boas (Bruch, 1978:18). ${ }^{5}$ Liu o exemplifica:

O jejum, no que me dizia respeito, era como uma competição entre o bem (abstinência) e o mal (indulgência). $\mathrm{Se}$ eu persistisse, purificar-me-ia. Enquanto continuasse a comer à minha maneira descontrolada, estava manchada (1979:109).

A comida é transformada de sustentação física em veículo de moralidade.

Como as medievais antes delas, as anoréxicas modernas têm uma relação distorcida com a comida. Em lugar de enfocar principalmente a nutrição dos outros, concentram-se em negar a si mesmas. A comida não serve mais principalmente para ligá-las aos outros, mas para permitir que transcendam seus egos mundanos $e$ terrenos na busca da perfeição.

\section{Jejum em Perspectiva Intercultural}

"Santas anoréxicas," "meninas que jejuam" e anoréxicas modernas compartilham outras características que aparecem em claro relevo quando contrastadas com o jejum de outros povos não ocidentais e não estratificados (Powdermaker, 1960). Tais diferenças fornecem uma chave para o entendimento das mulheres ocidentais e do significado de seu uso da comida. Em

\footnotetext{
5 A descrição de uma das estudantes sobre sua anorexia nervosa pautou-se na persistência cultural de certos temas relativos ao jejum extremo e indica que a busca de uma pureza religiosa e o ascetismo podem ainda ser um componente muito significativo dessa prática: "Eu me tornei um membro da Santa Igreja... Decidi praticar o ascetismo e sofri de anorexia nervosa. Tudo isso foi uma tentativa de controlar minha vida e agradar a Deus. Eu fazia dietas líquidas por dias e lia a bíblia por horas seguidas. Se eu tivesse desejos sexuais, fazia jejum para colocar meu corpo subjugado à bíblia - ou seja, pra me livrar do desejo sexual. A bíblia me encorajava a tornar-me um sacrifício vivo perante Deus. E eu o fiz. Estive além dos limites com minhas práticas para alcançar a graça divina".
} 
Uma visão antropológica do prodigioso jejum de mulheres ocidentais

todas as culturas, a comida é um símbolo importante: mas os significados atribuídos à comida e a maneira como ela é manipulada para formar mensagens variam amplamente entre culturas. ${ }^{6}$ Mary Douglas (1973:70) afirma que "o corpo humano é sempre tratado como uma imagem da sociedade" e que a passagem da "comida para dentro e para fora do corpo pode significar fronteiras sociais e sua transgressão. Mais importante para nossas questões é sua afirmação de que "o controle corporal é uma expressão do controle social" (id.ib.). O forte desejo de controlar a absorção de comida por parte das mulheres ocidentais é uma metáfora de seus esforços de controlar seus próprios corpos e destinos numa cultura que faz do autocontrole um imperativo moral. Isso, porém, revela questões ocidentais e não é um universal cultural.

Muitos povos não ocidentais praticam o jejum, ${ }^{7}$ mas raramente com a totalidade $e$ firmeza das mulheres ocidentais que jejuam (Katona-Apte, 1975:317-21; Messer, 1989). "A abstinência é seguida pela indulgência" (Goody, 1982:78) e festas regularmente interrompem períodos de consumo reduzido, como nos festivais de colheita que seguem austeros períodos anuais entre os gonja do norte de Gana. Os muçulmanos, por exemplo, quebram o jejum diário durante o Ramadan, cada noite, comendo abundantemente (Messina, 1988). Anorexia nervosa e mirabilis são, ao contrário, intermináveis.

Em sociedades tribais, o jejum é em geral coletivo e ritualizado. Um grupo social ou a sociedade como um todo evitarão certas comidas; seu jejum seguirá formas tradicionais, será dotado de significados específicos e será sancionado pela

6 Sobre o simbolismo da alimentação, ver por exemplo: Barthes, 1975; Douglas 1972; 1984; Kahn 1986; Lévi-Strauss 1969, Meigs 1984; Tambiah 1969; Verdier 1969; e Weismantel 1988.

7 Alguns exemplos bem documentados são os Gurage da Etiópia (Shack 1969; Shack 1971), Os Kalaunans da Ilha Goodenough (Young 1971, 1986), Os das Ilhas Trobiandesas, Melanésia (Malinowski, 1922), Os Siriono da Bolívia (Holmberg 1969), e os Bemba do Norte da Rodésia (Richards 1939). 
sociedade. Os LoDagaa do norte de Gana, referidos na obra de Goody, de 1982, fazem uma cerimônia anual bagre onde uma série de proibições alimentares é posta para iniciantes e gradualmente relevada durante um período de diversas semanas (cap. 3). O "cancelamento das proibições assume a forma de demonstração pública" (81) onde os meninos iniciados comem alimentos antes proibidos. Seu jejum temporário e parcial é seguido por uma festa pública e ganha significação pela celebração coletiva. Tanto a festa como o jejum - pelas capacidades de controlar $\mathrm{o}$ apetite, adiar $\mathrm{o}$ consumo $e$ compartilhar a comida - afirmam humanidade e sociabilidade. Ao contrário, o jejum ocidental que consideramos é solitário, às vezes secreto e não ritualizado publicamente.

$\mathrm{O}$ jejum dos povos não ocidentais comumente "demanda uma dieta alternativa mais que uma negação total" (Goody, 1982:117). Os Kalaunans da ilha Goodenough procuram "comidas secas e duras... para encher a barriga e satisfazer o apetite por longos períodos" mais que "comida macia e suculenta" (Young, 1986:116). Os habitantes das ilhas Trobriand fazem a mágica vilamalya para que sua comida cultivada dure por longo tempo fazendo com que se "inclinem a comer frutas silvestres do mato" (Malinowski, 1922:169). Meninos em iniciação entre os hua da Nova Guiné são desencorajados de comer certos alimentos associados com as fêmeas porque são considerados perigosos, mas são ao mesmo tempo estimulados a comer alimentos que se acredita que os fortificam e protegem (Meigs, 1984, cap. 2). Mesmo na cristandade medieval ocidental, a norma se limitava a jejum na sexta-feira, dias santos e Quaresma, quando a carne e comidas ricas eram desprezadas, mas comidas simples como pão, peixe, água e verduras eram permitidas (Bynum:40). De fato, como Bynum (47) e Bell (118 e ss.) observam, o jejum total era condenado pela Igreja, e muitas das santas anoréxicas enfrentavam forte oposição das autoridades da igreja - oposição que firmemente evitavam afirmando que eram incapazes de oporse à vontade de Deus pelo ato de comer. 
Uma visão antropológica do prodigioso jejum de mulheres ocidentais

A despeito da oposição eclesiástica, médica e social, as mulheres ocidentais têm jejuado até a morte pelo menos desde o século treze. Enquanto nas culturas tribais as pessoas nunca morrem (tanto quanto eu sei) de inanição voluntária, entre 15 e 19 por cento das anoréxicas graves morrem (Brumberg:13; Gordon, 1988). Brumberg documenta casos e mais casos de meninas que morreram por sua recusa a comer nos séculos dezessete, dezoito $e$ dezenove. Muitas das santas jejuadoras desejavam explicitamente a morte, entre elas Margarida de Cortona, que disse a seu confessor, depois que ele insistiu em que comesse,

Caro padre, não pretendo estabelecer a paz entre meu corpo e minha alma, nem pretendo desistir. Permita-me, então, domar meu corpo e não altere minha dieta; não vou parar pelo resto de minha vida até que não reste vida (citado por Bell, 101).

O jejum das mulheres ocidentais é anti-social, interminável, total e mortal; é diferente do que as pessoas praticam na maioria das outras sociedades. Talvez certas culturas na história compartilhem características que expliquem porque um número significativo de mulheres tenha jejuado até a morte. Considero aqui a significação causal da ideologia, da estrutura política $e$ econômica estratificada e da organização familiar patriarcal. Esses fatores são parcialmente descritos nos livros resenhados, que apresentam alguns dados sobre diferenças históricas; a consideração sistemática de sua inter-relação e similaridade ao longo do tempo podem iluminar a recusa de comida por parte das mulheres ocidentais.

\section{Ideologia}

O Absolutismo e a Busca da Perfeição

$\mathrm{O}$ jejum das mulheres ocidentais tem objetivos manifestamente diferentes em diferentes períodos históricos. Essas 
diferenças se relacionam ao processo geral de secularização (Bell:170-77; Brumberg, passim) e a diferenças significativas na cultura. Mas, mesmo quanto o ocidente ficou manifestamente menos religioso, certos princípios religiosos persistiram porque estavam profundamente entranhados na cultura ocidental. A ideologia judaico-cristã - diferentemente da de muitas outras sociedades - é tanto dualista quanto absolutista, baseada numa

\begin{abstract}
dicotomia de absoluta bondade e maldade, de absoluta força $e$ fraqueza, absoluta verdade $e$ inverdade... A orientação judaico-cristã contrasta pecado e virtude, graça e não graça, queda e redenção, a fim de compreender o papel do divino na sustentação do bem, da virtude e assim por diante. No esquema geral do pensamento judaicocristão é necessário ter contrastes diametralmente opostos, $e$ dentro das vidas dos indivíduos uma pessoa julga a virtude de sua vida presente, alcançada pela graça de Deus, com seu passado em pecado (Pandian, 1985:50).
\end{abstract}

Durante a Idade Média, observa Pandian (1985:51), a cultura ocidental perdeu "o acervo conceitual do grande alcance da possibilidade e da auto-identidade humanas" que fora apresentado pela mitologia grega com seu conjunto de deuses ciumentos, sábios, tontos, irados, compostos, fracos, poderosos e assim por diante. O que sobrou foi a perfeição simples $e$ radicalmente contrastada com a perdição.

As mulheres medievais perseguiam a santidade pelo jejum, as meninas vitorianas buscavam a devastação e a fraqueza associadas à superioridade social e espiritual, $e$ as mulheres modernas buscam a magreza - todos aspectos da perfeição no sistema de valores de suas culturas. William Davis sugere que "tanto a magreza quanto a santidade representam estados ideais do ser nos meios culturais considerados" (1985:181-82). Brumberg diz que "a anorexia nervosa parece ser uma adesão secular a um novo tipo de perfeccionismo que liga a salvação pessoal à obtenção de uma configuração externa do corpo em lugar de um 
Uma visão antropológica do prodigioso jejum de mulheres ocidentais

estado espiritual interno" (7). Assim, as mulheres procuram persistentemente atingir um estado absoluto de perfeição pelo jejum, mas alteram a definição da perfeição à medida que suas sociedades se tornam cada vez mais secularizadas.

A persistência da ideologia absolutista no tempo está implicada no modo obsessivo em que as mulheres jejuam. A recusa da comida deve ser total; qualquer coisa menos deixa de atingir o desejado estado de perfeição. Ainda que muitas santas medievais, como Catarina de Siena (Bell, cap. 2; Bynum:169) e Margarida de Cortona (Bell:101) recebessem de seus confessores a ordem de se alimentar, elas recusavam na crença de que o jejum total era essencial para sua santidade e união com Deus. Brumberg documenta muitos casos de mulheres nos séculos dezessete, dezoito e dezenove, como Ann Moore (60) e Sarah Jacob (64 e ss.), que pretendiam ou de fato recusavam toda comida, pois a impressão do jejum total era parte de seu autoconceito e de seu impacto sobre os outros. As anoréxicas modernas aderem tenazmente a uma dieta rígida e sentem que qualquer transgressão prejudica sua busca de realização. Como diz Aimee Liu (1979:40), "Estou ficando famosa na escola por minha exibição de auto-disciplina... A esse respeito, sou a melhor, mas se deixar cair, tudo está perdido, de modo que me prendo à minha dieta tenazmente". Mas o jejum total é doloroso e difícil demais para a maioria das mulheres, $e$ assim muitas que perenemente se submetem a dietas ou que são bulímicas graves oscilam perigosamente entre o jejum e a indulgência, a superalimentação e a purga, consumidas pela culpa em relação a seu fracasso em jejuar, em manter uma dieta com perfeição.

\section{Dualismo Corpo-Mente e Rebaixamento da Mulher}

Outro fundamento persistente da ideologia ocidental é que é diferente de muitos povos tribais não ocidentais é a dicotomia de mente e corpo (Pandian, 1985). A literatura aqui resenhada sobre as mulheres medievais, vitorianas e modernas que jejuam deixa 
claro que crenças na separação entre mente e corpo e o valor moral do domínio do corpo pela mente são importantes para essas mulheres (ver também Bordo, 1993; Chernin, 1981). Brumberg (77 e ss.) nos diz, por exemplo, que o jejum de quatorze dias do "enigma de Brooklyn", Mollie Fancher, era visto por seus seguidores espiritualistas como evidência da "dualidade de corpo e mente" (87).

Essa dualidade é parte integrante da moralidade ocidental desde o tempo dos antigos gregos (Bell:118-19). Os dois modos principais de realizar o controle da mente sobre o corpo são o jejum e a castidade. Bynum (2) argumenta que para o povo medieval, "reprimir o ato de comer e passar fome era controlar o corpo numa disciplina muito mais básica que qualquer outra alcançada desprezando as satisfações menos frequentes $e$ essenciais do sexo ou do dinheiro." Para os vitorianos, a sexualidade era estritamente controlada e "o apetite era visto como um barômetro da sexualidade" (Brumberg:175); portanto, a negação do apetite equivalia à supressão da sexualidade. $\mathrm{Na}$ sociedade moderna, o controle da ingestão de alimentos assumiu uma grande importância na demonstração da moralidade. $\mathrm{O}$ controle sexual pode ter se tornado relativamente desimportante, mas a limitação da comida em meio à afluência, da constante disponibilidade de comida e da incessante promoção do consumo pela propaganda é difícil e altamente considerada (Brumberg, Afterword; Mackenzie, 1976; Schwartz, 1986).

$\mathrm{Na}$ tradição dualista ocidental, as mulheres são identificadas com a natureza e o corpo sensual que deve ser controlado, e os homens são associados à cultura e à mente que controla (Bynum:282; Chernin, 1981), como na história de Adão, a mente que duvida, tentado por Eva, a carne libertina (ver Chernin, 1987). Mulheres que buscam valor e dignidade nos termos definidores da cultura ocidental devem dominar seus apetites com sua vontade, afirmando assim sua espiritualidade, disciplina e moralidade. Numa cultura que postula o domínio da mente sobre a sensibilidade e associa as mulheres com o corpo e seus apetites, o 
Uma visão antropológica do prodigioso jejum de mulheres ocidentais

fardo do controle cai de modo particularmente pesado sobre as mulheres.

Por causa da descrição das mulheres na visão dicotômica do mundo, sua busca pela perfeição precisa da dominação do corpo pelo controle do consumo de comida e da resistência à fome. Bynum e Bell descrevem muitas vezes como as mulheres medievais torturavam a si mesmas tentando reprimir sua fome num esforço para virar santas. A dor e o sofrimento eram igualadas ao prazer e ao amor (Bell:60), e a fome representava "a fome de Deus" (Bynum:152). A mística flamenga Hadewijch, do século treze, por exemplo, escreveu belos poemas místicos expressando sua crença de que "a fome... é a incorporação com a humanidade sofredora do Cristo, com nossa via à sua divindade. Quanto mais passamos fome com Cristo, mais somos preenchidas" (Bynum:160). Brumberg mostra como as mulheres vitorianas achavam o apetite vulgar, não feminino, não espiritual $e$ imoral (cap. 7). A comida era associada com status de classe baixa, trabalho e labuta, glutonaria e feiura física; o apetite era associado à sexualidade e à falta de auto-restrição (178-79). Abstinência de comida significava refinamento social, delicadeza, capricho $e$ moralidade - as características mais admiradas pelas damas vitorianas. De modo similar, as anoréxicas, como Aimee Liu (1979:40), definem sua dignidade em termos da autodisciplina que reúnem para limitar o consumo.

Ao mesmo tempo em que afirma a importância do dualismo corpo-mente como contexto significativo do jejum das santas, Bynum também afirma que as mulheres medievais não expressavam apenas uma misoginia cultural internalizada baseada no masoquismo ou no dualismo (208). Ao contrário, diferentemente das anoréxicas modernas, elas assumiam poder $e$ faziam uma afirmação positiva com seu jejum. Ela de fato diz que a Idade Média tinha uma lição para os modernos:

Na Idade Média, as pessoas viam a comida e o corpo como fontes da vida, repositórios de sensações. Assim, a comida e 
o corpo significavam capacidade de gerar e de sofrer. A comida, que devia ser destruída para dar vida, e o corpo, que devia ser forçado para dar à luz, passaram a ser sinônimos; identificando-se com os dois, as mulheres conseguiram dar sentido a uma existência física, humana, em que o sofrimento era inevitável... Em contraste, os modernos veem comida e corpo como recursos a serem controlados. Assim, comida e corpo significam aquilo que ameaça o domínio humano... Corpo e comida são então símbolos do fracasso de nossos esforços para controlar a nós mesmos (300).

Bynum sublinha uma diferença importante nas atitudes medievais e modernas em relação ao sofrimento. Na Idade Média, as mulheres festejavam a agonia corporal, que viam como redentora; embora o corpo pudesse ser uma fonte do mal, seu sofrimento também podia trazer a salvação. As mulheres vitorianas viam o sofrimento com ruidosa reverência, como uma via para a delicadeza corporal (Brunberg, cap. 5). As mulheres modernas tentam negar o corpo e sua dor, que representam o fracasso da mente em sua capacidade de controlar os sentidos. A despeito dessa diferença, as mulheres que jejuam compartilham tanto uma crença no corpo como fonte potencial do mal quanto o temor de sua própria suscetibilidade à tentação. Embora Lois Paul (1974) relate crença semelhante entre as mulheres maias (fortemente influenciadas pelo cristianismo) e muitas culturas definam o corpo feminino como poluidor (Douglas, 1966; Meigs, 1984; Delaney, Lupton e Toth, 1988), não conheço qualquer cultura onde as mulheres tentem purificar seus corpos com a recusa total $e$ inexorável de comida que caracteriza as anoréxicas santas, vitorianas e modernas.

Negação da sexualidade e reprodução femininas

Uma característica compartilhada das mulheres ocidentais que jejuam excessivamente é a negação de seu potencial 
Uma visão antropológica do prodigioso jejum de mulheres ocidentais

reprodutivo e de sua sexualidade. Isso, acredito, deriva da atitude ambivalente dos judeu-cristãos em relação ao corpo, fonte ao mesmo tempo da vida e da tentação. Todas as jejuadoras, incluindo as medievais (Bynum:138, 148, 214, 217), as vitorianas (Brumberg:132) e as modernas (Brush, 1973:275), deixam de menstruar e suas curvas femininas desaparecem. Uma pessoa que passa fome perde todo desejo sexual (Firth, 1959; Holmberg, 1969; Turnbull, 1972; Winnick, 1979). Como observou Margaret Mead (1967:144), para as mulheres tanto comer quanto o intercurso sexual envolvem incepção; parar de comer pode significar negação da incepção, inclusive a sexual. $\mathrm{O}$ apetite e o instinto sexual, a boca e a vagina, estão simbolicamente ligadas (Freud, 1962:1); fechar a boca para a comida representa fechar a vagina para o sexo.

O temor, o desagrado e a recusa da ligação sexual são temas comuns nas visões de mundo das santas medievais e das anoréxicas e estão ligadas à sua recusa da comida. Ainda que discussões explícitas sobre sexo sejam raras entre as anoréxicas do século dezenove, há evidências de que "expectativas confusas ou não realizadas no domínio do namoro foram agentes precipitadores e comuns nas desordens mentais de meninas adolescentes" (Brumberg:134-35). Numerosos estudos sobre mulheres contemporâneas com distúrbios alimentares relatam a hostilidade delas ao contato sexual com homens (Orbach, 1978; Millman, 1980:188-89; Chernin, 1981; Brush, 1973:175-80). Aimee Liu (1979), por exemplo, diz, "Meu Deus, como eu odiava os homens! Eles me provocavam arrepios na pele. Pior, faziam com que me desprezasse, meu corpo, meu sexo. Eles eram bastardos, é verdade, mas era a minha carne que os excitava. Ugh, era uma coisa abominável. Tinha que haver uma saída, tornar-me andrógina" (id.ib.:101). E assim ela parou de comer, deleitou-se com o desaparecimento da menstruação e dos seios, e desejou "voltar ao corpo de uma criança" (41). Sua atitude é semelhante à da freira Francesca Bussa, dominicana do século catorze, que recusava comida como parte de seu horror total ao sexo: 


\begin{abstract}
A consumação do casamento, quando tinha treze anos, teve um efeito imediato e traumático na menina; tão logo terminou a celebração do casamento, sem aviso, ela repentinamente perdeu toda a força, ficou paralisada $e$ muda, e totalmente incapaz de comer... Aos dezessete ou dezoito, Francesca tinha reduzido sua alimentação a uma refeição por dia, e essa, espartana ao extremo: nada de peixe, de ovo, galinha ou qualquer coisa doce ou delicada, apenas legumes amargos e feijão, sem azeite... Dormia apenas duas horas por dia e mesmo durante esse tempo dizia ser torturada por sonhos com homens que carregavam gigantescas cebolas cozidas (alimento que ela detestava $e$ que sempre a nauseava) $e$ a esfregavam em seu rosto $e$ a enfiavam em sua boca (Bell:136-38).
\end{abstract}

O absolutismo, o dualismo e timidez em relação à sexualidade feminina, características da ideologia judeu-cristã, formam o contexto para as mulheres que exibem forte ambivalência em relação a seus apetites sensuais. Elas os negam, mas são atormentadas por pensamentos sobre comida ou por demônios sexuais. Tentam reprimir seus desejos, mas a negação constante apenas os exacerba. A negação dos apetites do corpo une as jejuadoras ocidentais e fornece uma via para a autonomia e realização individuais onde não existe outro caminho.

\title{
Patriarcado e subordinação feminina
}

A perspectiva totalizante e comparativa pode iluminar como o jejum de mulheres ocidentais se relaciona com sua posição social e econômica subordinada que evolui historicamente e que limita os canais para sua auto-expressão. Bell, Bynum e Brumberg, cada uma a sua maneira, levantam e tratam da questão de saber se esse jejum é uma resposta e uma luta contra o patriarcado. ${ }^{8}$ Até certo ponto, elas, como muitos estudiosos

\footnotetext{
8 A principal afirmação de Bell é que "historicamente, um grupo significante de mulheres exibiram um padrão comportamental de anorexia em resposta às
} 
Uma visão antropológica do prodigioso jejum de mulheres ocidentais

contemporâneos da anorexia nervosa, acreditam que sim. Embora apresentem importantes idéias relacionadas à questão, nenhuma delas oferece uma definição explícita do patriarcado, nem uma clara exposição de como o jejum das mulheres constitui um protesto contra ele.

De uma perspectiva antropológica, patriarcado é uma sociedade onde as mulheres são política, econômica, social e ideologicamente desvalorizadas e estão em desvantagem, onde não têm controle de recursos econômicos e de poder e onde são consideradas moral e fisicamente inferiores aos homens. Não há nos três livros uma análise sistemática do lugar das jejuadoras num sistema de desigualdades de classe e gênero, mas eles dão alguma informação.

Algumas das santas jejuadoras vinham de famílias urbanas com recursos (Bynum:18). As anoréxicas modernas são predominantemente de famílias brancas de classe média alta, ou de famílias ascendentes de classe média baixa (Bruch, 1978; Lawrence, 1984), com uma incidência em torno de um caso em cada cem das norte-americanas e entre um e vinte casos severos

estruturas sociais patriarcais nas quais estavam enredadas" (xii). Santas medievais, afirma Bell, lutaram contra sua posição social subordinada, exaltando sua vontade de jejuar como forma de contornar a autoridade masculina $e$ estabelecer uma conexão direta com Deus. Diferentemente de Bell, Bynum (208) afirma que as santas medievais não são vítimas do patriarcado (295). Embora alguns hagiógrafos masculinos as tenham descrito assim, Bynum argumenta que elas estavam exercendo poder e estabelecendo uma conexão direta com Deus através do jejum e não apenas reagindo contra a dominação masculina. $\mathrm{O}$ desejo de Brumber é de não reduzir um conjunto de comportamentos femininos à mera oposição ao masculino, por isso, não caracteriza o jejum feminino como reação contra o patriarcado, ao invés disso, enfatiza a diversidade de objetivos $e$ significados dessas práticas ao longo do tempo (37). Contudo, seu livro registra claramente relações de dominação-subordinação entre intérpretes masculinos das mulheres praticantes de jejum. Além disso, sua proposição para reduzir a incidência de anorexia na contemporaneidade implica dar às mulheres um sentido de valor ao seu próprio sexo e suporte às "suas aspirações específicas e sua criatividade feminina em geral" (269), dando a entender que esse jejum autodestrutivo está relacionado à sua subordinação. 
em cada cem de meninas de curso médio e universitárias (Brumberg:280; Emmons, 1992; Hsu, 1987; Parker et alii, 1995). Foi sugerido que as negras granjeiam mais respeito que as brancas dentro da família e da comunidade e que o controle das trocas de comida é fonte importante de seu poder (Stack, 1974; Styles, 1980). Muitos dos exemplos de Brumberg do século dezenove eram de classe média, como Mollie Fancher, "de uma família moderadamente respeitável, inteligente e bem relacionada" (Brooklyn Daily Eagle, 7 de junho de 1866, citado por Brumberg, 79). Outras tinham origem mais humilde (47): Ann Moore era filha de um trabalhador (56), e Sarah Jacob era uma dos sete filhos de lavradores na Gales rural (64). De fato, diz Brumberg, "as jovens jejuadoras do final do século dezenove não eram em geral filhas da burguesia urbana educada ou com espírito secular" (91). Eram, ao contrário, as últimas relíquias "de uma cultura religiosa feminina mais antiga" (100). Mais dados sobre as jejuadoras são necessários para testar a sugestão de Pamela Ouaggiotto (1987) de que talvez as mulheres tenham decidido jejuar para reafirmar-se como sujeitos, posição que lhes foi negada quando seu trabalho se tornou supérfluo. A sociedade ocidental mudou enormemente desde a Idade Média, é claro, mas ao longo do tempo algumas mulheres tiveram uma posição particularmente impotente, secundária e muda, comparadas com mulheres em sociedades não hierárquicas e não ocidentais.

Antropólogos (p. ex., Brown, 1975; Lee, 1979; Murphy e Murphy, 1985; Shostak, 1981; Weiner, 1988) documentaram inúmeros casos de sociedades não estratificadas onde as mulheres têm muita influência através de seu controle de recursos e seu papel importante na produção, distribuição, preparação $e$ consumo de comida. Entre os iroqueses, por exemplo, as mulheres tinham poder considerável porque produziam os alimentos mais importantes - milho, feijão e abóbora, as "três irmãs" - e porque controlavam a distribuição, que era o principal canal para criar obrigações por parte dos outros (Brown, 1975). As iroquesas também detinham os estoques de comida (importante 
Uma visão antropológica do prodigioso jejum de mulheres ocidentais

fonte de riqueza) e usavam esse controle para influenciar as decisões políticas.

Mas, à diferença de suas irmãs tribais, muitas das mulheres ocidentais que praticaram o jejum não controlam recursos econômicos importantes, nem trabalham ativamente na produção, nem administram a distribuição; elas administram apenas a preparação e o consumo dos alimentos, geralmente dentro de casa. Embora Bell (p. ex., 88) e particularmente Bynum (cap. 7) mencionem como as mulheres medievais evitavam a autoridade masculina distribuindo comida para os pobres, esse não era um propósito legítimo; o ato incitava opróbrio da parte dos pais, maridos e autoridades religiosas. $O$ controle do consumo é o principal canal de expressão da identidade, influência e vontade das mulheres ocidentais. A recusa à comida produzida e dada por outros é, como discutimos acima em referência a Mauss, uma recusa a ser controladas. O jejum é um dos poucos meios legítimos de as mulheres exercerem controle sem desafiar abertamente o poder masculino. Essa é talvez a razão por que elas são obcecadas com comida e jejum de um modo que as mulheres não ocidentais, que têm outros canais de influência, não são.

\section{Família, Jejum, Autonomia e Relações}

A sociedade ocidental patriarcal não só restringe as oportunidades econômicas e políticas das mulheres, mas também define seu papel dentro da família como nutriz e fornecedora de comida, papel compatível com o uso de comida como voz. Embora a maioria das mulheres na sociedade ocidental tenha sido relativamente impotente, só algumas escolheram o jejum extraordinário. São mulheres que, por causa de experiências familiares específicas, podem ter tido dificuldades psicológicas particularmente severas com autonomia, intimidade e com o ato de comer. Pesquisadores da anorexia nervosa contemporânea sugeriram que ela está relacionada a dinâmicas familiares específicas (p. ex., Bruch, 1973, 1978; Lawrence, 1984; Minuchin, 
Rosman e Baker, 1978). Desordens alimentares surgem em particular em famílias onde os pais se preocupam com a perfeição e se envolvem e identificam excessivamente com os filhos, e são super-protetores, restringindo sua independência e autonomia. Além disso, distúrbios alimentares são prováveis em famílias onde os pais confundem comida com amor e deixam de responder apropriadamente às necessidades dos filhos, interferindo com sua capacidade de reconhecer fome e saciedade e de usar a comida de modo apropriado (Bruch, 1983, cap. 4). Alguns pais são, eles mesmos, excessivamente preocupados com a relação entre comida, o corpo e a própria dignidade. Veem o consumo de comida principalmente como via para a retidão moral. $\mathrm{O}$ modo como esses padrões familiares estão implicados nos distúrbios alimentares modernos está bem estabelecido, mas a escassez de dados sobre as relações familiares das jejuadoras medievais $e$ vitorianas torna difícil dizer se padrões semelhantes existiram nos casos de jejuadoras do passado.

A recusa da comida é negação de relação e o jejum até a morte é a ruptura final da conexão humana. Dificuldade com a intimidade e a relação é um tema claro em todo jejum feminino ocidental, que é auto-centrado e narcisista. As santas medievais se voltavam para dentro à procura de Deus nelas mesmas; como escreveu Catarina de Gênova, "Meu Eu é Deus" (Bynum:277). As anoréxicas modernas se tornam totalmente envolvidas consigo mesmas; como escreve Aimee Liu, "Os espelhos, este e o grande espelho de parede sobre a pia no banheiro, desempenham parte importante em minha vida agora. Durante horas cortejo minha imagem diante deles" (1979:75). As jejuadoras medievais, vitorianas e modernas têm vidas solitárias e poucos amigos; de fato, adesão ao jejum e a rotina ascética envolvem horas de reclusão a cada dia, deixando pouco tempo para relações com os outros.

Em seu epílogo ao livro de Bell, William Davis oferece uma hipótese interessante para explicar a volta sobre si mesmas das jejuadoras. Ele se refere à descoberta de Carol Gilligan (1981) de 
Uma visão antropológica do prodigioso jejum de mulheres ocidentais

que a identidade feminina se baseia em relações e sugere que as jejuadoras têm uma forte necessidade de uma conexão sobrehumana. A santa jejuadora procurava e estabelecia uma ligação direta com Deus, não mediada pela autoridade masculina. "Ela queria acima de tudo ser profundamente ligada a si mesma, independente das necessidades que a levariam inevitavelmente a uma relação hierárquica, submissa e "possuída' com homens" (184). As anoréxicas modernas "ignoram a filiação e se concentram em adquirir poder" (185); acham-se totalmente privadas do senso de identidade que as mulheres alcançam através das relações. Menos clara é a dificuldade das jovens vitorianas de classe média com as relações: talvez o fato de que suas "opções de auto expressão fora da família fossem limitadas pelo cuidado familiar e convenção social" (Brumberg, 188).

A família é o terreno mais imediato para a recusa de comer das meninas, e é o domínio mais radicalmente perturbado por seu jejum. Brumberg descreve com competência a recusa de comida por parte das meninas do século dezenove como uma "impressionante disfunção do sistema familiar burguês" (134). Muitos pesquisadores levaram em conta o papel da dinâmica familiar, particularmente da relação mãe-filha, como causa da anorexia nervosa contemporânea. Feministas como Susie Orbach (1978, 1982) e Kim Chernin $(1981,1985,1987)$ sugeriram que a relação mãe-filha é extremamente problemática numa sociedade patriarcal onde as filhas se identificam com suas mães, mas não podem respeitá-las por causa da posição subordinada delas. As mães querem que as filhas tenham sucesso, mas inibem o desenvolvimento delas porque isso destacaria a falta de sucesso das próprias mães. As meninas respondem buscando a autonomia e a excelência por um canal que atinge as mães literalmente nas entranhas, mas não ameaça as escolhas delas.

A discussão de Brumberg sobre "amor e comida na família burguesa" na era vitoriana (cap. 5) mostra como os conflitos familiares podem resultar em anorexia nervosa. Nesse meio social, a comida tinha importância central; as filhas dependiam da família 
por longo período; e a família, particularmente a relação entre mãe e filha, era opressiva. A jovem do século dezenove era símbolo e veículo do empenho social materno; seu consumo de comida refletia amor, status social e etiqueta. A jovem vitoriana sufocada pela possessividade e aspirações familiares encontrou uma forma perfeita de rebelião na recusa à comida. Era um modo de protestar contra a natureza opressiva das relações sem rompêlas e simbolizava claramente a ambivalência da jovem em relação às ligações familiares.

Há alguma evidência de que as jejuadoras medievais estavam envolvidas em lutas semelhantes pela autonomia com suas mães. Maria Madalena de Pazzi, por exemplo, "travava suas batalhas emocionais mais severas" com sua mãe e competia com ela pela santidade e pela afeição do pai (Bell:172). Bell diz de Catarina de Siena, uma das mais dramáticas e influentes das santas anoréxicas:

\begin{abstract}
Numa competição de vontades tão comum $e$ ordinariamente trivial como o desmame, a mãe Lapa tinha que triunfar sobre a filha Catarina, mas como adulta essa criança garantiu nunca perder tais batalhas, redefinindo muitas vezes uma situação em sua mente de tal maneira que o que poderia aparecer aos outros como obediência neste mundo era para ela um triunfo no próximo para o prometido a quem ela estava unida (32).
\end{abstract}

Em famílias medievais, vitorianas e modernas, as jejuadoras são aquelas com uma necessidade especial de autonomia. Frequentemente elas são mulheres particularmente inteligentes, diligentes, criativas ou imaginativas que se sentem especialmente aprisionadas pelo confinamento de seu papel social. A maioria das anoréxicas contemporâneas é realizadora, ostensivamente bem sucedida na escola, nos esportes e na vida até o advento do distúrbio (Bruch, cap. 3). Muitas das santas anoréxicas também eram mulheres incomuns: ambiciosas, perfeccionistas, articuladas, poéticas, capazes de devoção fanática a seu jejum religioso, 
Uma visão antropológica do prodigioso jejum de mulheres ocidentais

alegres, sociáveis e impetuosas (Bell, 114). Embora Bell documente todo um grupo de santas anoréxicas que passaram a assumir esse comportamento depois do casamento e do nascimento de filhos (cap. 4), a maioria das jejuadoras medievais (Bynum, 119), vitorianas (Brumberg, passim) e modernas (Bruch, 1978, cap. 4) parece começar ou intensificar seu comportamento extraordinário na adolescência, período em que a relação mãe-filha se torna particularmente difícil à medida que a filha começa a definir sua identidade feminina adulta. Por causa da centralidade e significação da comida para as mulheres e de sua falta de outros meios (Bynum, cap. 6), as mulheres usam sua recusa como principal veículo em sua busca de identidade, relação e autonomia.

Alimentação traumática na infância pode explicar por que algumas mulheres se tornam jejuadoras, ao passo que outras, com problemas culturais e psicológicos semelhantes, não. A psicologia freudiana, como discutem tanto Brumberg (213) quanto Bell (11), deu atenção a esse ponto. Num trabalho precursor, Anna Freud (1946) estendeu muitas das noções implícitas de seu pai sobre a importância da alimentação no estabelecimento da personalidade da criança, de sua relação com a mãe e de sua atitude posterior em relação à comida. ${ }^{9}$ Bruch (1973, cap. 4) descobriu que o fracasso dos pais em ensinar às crianças o reconhecimento apropriado de fome e saciedade, e a resposta a elas, era a base de muitos dos distúrbios alimentares de suas pacientes. Bell acredita que padrões de relações futuras são determinados pela consistência ou inconsistência da amamentação. Por exemplo,

9 Anna Freud (1946:126) acredita que os problemas comportamentais de crianças em relação à comida derivam de conflitos emocionais em relação à mãe, que são simbolicamente transferidos para a comida. Essa ambivalência em relação à mãe pode expressar-se através de flutuações entre excesso e recusa por comida; sentimentos de culpa em relação à mãe e uma consequente dificuldade para desfrutar de sua afeição como inabilidade para desfrutar da comida; obstinação e hostilidade contra a mãe como uma luta contra ser alimentado por ela. 
atribui a grande capacidade de Catarina de Siena para a fé a seu "contentamento oral" na infância (30-35) e a turbulência espiritual e psicológica de Catarina de Racconigi ao fato de que sua mãe não tinha leite e "mandava a criança nos braços de seu irmão Luigi para pedir amamentação de mulheres mais saudáveis da aldeia" (159).

Antropólogos apresentam dados que dão uma perspectiva interessante sobre como a alimentação traumática na infância pode afetar a personalidade adulta $e$ as atitudes em relação à comida sem causar anorexia nervosa. Dorothy Shack (1969) e William Shack (1971) argumentam que a alimentação inconsistente de crianças entre os gurage da Etiópia, inclusive a privação quando com fome e a alimentação forçada quando saciados, é responsável por vários traços de personalidade entre os adultos gurage, aí incluídos o egoísmo, o distanciamento emocional, a passividade, a dependência, sentimentos de falta de ocupação e ansiedade por comida. Os gurage de status baixo, os mais privados de comida e mais sujeitos a dependência-frustração pela mãe, sofrem possessão por espíritos que lembra a anorexia nervosa, embora diferente dela. Ela se caracteriza pela perda de apetite, náusea e dores de estômago (Shack, 1971:35). O espírito é exorcizado num ritual coletivo onde os parentes da vítima o alimentam com comida cerimonial especial até que o espírito grita de dentro dela "Estou satisfeito" (36). O caso dos gurage mostra que distúrbios psicológicos se expressam pela alimentação em sociedades tanto ocidentais quanto não ocidentais e que distúrbios psicológicos centrados na comida podem ser de fato determinados por alimentação não apropriada na infância e pela dinâmica familiar, mas também mostra que o sexo da vítima e o uso de comida para resolver o distúrbio dependem da situação cultural, social, econômica e psicológica específicas. Os dados sobre os gurage apoiam a afirmação de Brumberg de que os distúrbios alimentares são multi-determinados e dependem da "vulnerabilidade biológica do indivíduo, da predisposição psicológica, da família e do clima social" (24). 
Uma visão antropológica do prodigioso jejum de mulheres ocidentais

\section{Conclusão}

A perspectiva totalizante e intercultural da antropologia pode ajudar a explicar o extraordinário jejum de mulheres ocidentais ao longo de oitocentos anos pondo em relevo um conjunto semelhante, ainda que não idêntico, de forças culturais que influenciaram sua relação com a comida e o corpo. Uma visão do mundo dualista e absolutista estabeleceu um contexto em que uma negação total do apetite é um caminho significativo $e$ admirado para a perfeição. A sociedade patriarcal relegou as mulheres a uma posição secundária em virtude de seu sexo. Algumas - talvez particularmente ambiciosas e empreendedoras, agrilhoadas por famílias opressoras - procuram uma voz e lutam contra a subordinação recusando comida. Escolhem o jejum por causa da crença ocidental de que a mente deve dominar o corpo e por causa da importância da comida em suas vidas. É o recurso mais importante que elas controlam, mesmo quando apenas controlam seu consumo. A negação da comida e do apetite traz a seus praticantes dignidade moral, admiração $e$ os estados desejados de santidade, delicadeza ou magreza, estados efêmeros que podem envolver a inteira negação das jejuadoras, através da morte.

A relação autodestrutiva que as mulheres ocidentais têm com o corpo e a comida é, afirmo, significativamente diferente daquela das mulheres em muitas culturas não ocidentais, por razões que demandam mais pesquisas tanto de historiadores quanto de antropólogos. Precisamos de mais dados para responder às questões levantadas por este ensaio: Como o desenvolvimento do capitalismo afetou e alterou a relação das mulheres com seus corpos, a comida e o jejum? Como a mercantilização do corpo, especialmente o corpo feminino, pela moda e pela arte (Berger, 1972; Nochlin, 1988) contribuiu para o fortalecimento ideológico da subordinação feminina e para a alienação das mulheres em relação a seus seres físicos manifesta no jejum extremo? Expressa o jejum incessante os esforços delas 
para tornar-se atores sociais significativos no contexto do caráter economicamente supérfluo de seu trabalho? Jejuam as mulheres até a morte de modos semelhantes em contextos culturais onde são atores significativos? Como podemos explicar a anorexia nervosa das japonesas contemporâneas observada por Gordon (1988) e Brumberg (13, 280-81, n. 15)? Em que medida ela é causada pela "rápida ocidentalização" 4 ou por outras forças culturais internas, e que luz isso lança sobre nossa compreensão da recusa à comida por mulheres ocidentais? Finalmente, como explicar a anorexia nervosa entre homens sem invalidar afirmações de que o jejum ao longo dos séculos está intimamente ligado à experiência específica das mulheres? Acredito que alguns homens se tornam jejuadores porque compartilham a subordinação feminina, a falta de saída significativa para a autoexpressão e a ideologia moral absolutista que valoriza o ascetismo, ainda que outros homens possam jejuar por diferentes razões, que precisam de investigação adicional. Temo que, enquanto a cultura ocidental negar a muitas mulheres (e a alguns homens) oportunidades de auto-realização, poder e relação significativa; enquanto as fechar em famílias opressivas e trivializar a figura da mãe; e enquanto insistir num padrão absoluto de perfeição, algumas mulheres continuarão a voltar-se para a manipulação, às vezes fatal, de seu próprio consumo de comida como meio de auto-definição.

\section{Referências bibliográficas}

BARTHES, Roland. Toward a psychosociology of contemporary food consumption. In: FOSTER, Elborg e FOSTER, Robert (eds.). European diet from pre-industrial do modern times. New York, Harper and Row, 1975 [1961]. Reprinted in Counihan, Carole e Van Esterik, Penny. Food and Culture: a reader. New York, Routledge, 1997.

BELl, Rudolph M. Holy Anorexia. Epílogo de William N. Davis. Chicago, University of Chicago Press, 1985.

BERGER, John. Ways of seeing. New York, Penguin, 1993. 
Uma visão antropológica do prodigioso jejum de mulheres ocidentais

BORDO, Susan. Unbearable weight feminism, western culture and the body. Berkeley, University of California Press, 1993.

BOSKIND-LODAHL, Marlene. Cinderella's stepsisters: a feminist perspective on anorexia nervosa and bulimarexia. Signs 2, 1976, pp.342-56.

BOSKIND-WHITE, Marlene e WHITE, William C. Bulimarexia. The binge/purge cycle. New York, Norton, 1983.

BROWN, Judith K. Iroquois women: na ethnohistorical note. In: REITER, Rayna R. (ed.) Toward na anthropology of women. New York, Monthly Review, 1975.

BRUCH, Hilde. Eating disorders: obesity, anorexia nervosa and the person within. New York, Basic Books, 1973.

. The golden cage: the enigma of anorexia nervosa. New York, Vintage, 1978.

. Conversations with anorexics. New York, Basic Books, 1988.

BRUMBERG, Joan Jacobs. Fasting Girls: The Emergence of Anorexia Nervosa as a Modern Disease. Cambridge, Harvard University Press, 1988.

Bynum, Caroline Walker. Holy Feast and Holy Fast: The Religious Significance of Food to Medieval Women. Berkeley, University of California Press, 1987.

CHERNIN, Kim. The obsession: reflections on the tyranny of slenderness. New York, Harper and Row, 1981.

. The hungry self. New York, Times Books, 1985.

. Reinventing eve: modern woman in search of herself. New York, Times Books, 1987.

COUNIHAN, Carole M. Food, culture and political economy: an investigation of changing food habits in the Sardinian Town of Bosa. Ph. D. diss., University of Massachusetts, Amherst, 1981.

. An Anthropological View of Western Women's Prodigious Fasting. A review essay. Food and Foodways 3, 4, London, Routledge, 1989, pp.357-75.

DALly, Peter. Anorexia nervosa. New York, Grune \& Scratton, 1969. 
D'ANDRADE, Roy. Sex differences and cultural institutions. In: LEVINE, Robert A. Culture and personality: contemporary readings. New York, Aldine, 1974.

DAVIS, William N. Epilogue. In: BELL, Rudolph M. Holy anorexia. Chicago, University of Chicago Press, 1985.

DELANEY, Janice; Lupton, Mary Jane e Toth, Emily. The curse: a cultural history of menstruation. Urbana, University of Illinois Press, 1988.

DOUGLAS, Mary. Purity and danger. Londres, Routledge \& Kegan Paul, 1966. . Deciphering a meal. Daedalus 101, 1972, pp.61-82.

. Natural symbols: explorations in cosmology. New York, Pantheon, 1973.

. Food in the social order: studies of food and festivities in three american communities. New York, Russell Sage Foundation, 1984.

EMMONS, Lillian. Food procurement and the nutritional adequacy of diets in low-income families. Journal of the American Dietetic Association 86 (12), 1986, pp.1684-93.

FIRTH, Raymond. Social change in Tikopia: restudy of a polynesian community after a generation. New York, Macmillan, 1959.

FREUD, Anna. The psychoanalytic study of infantile feeding disturbances. The psychoanalytic study of child. An. Annual, vol. 2. In: CouniHAN, Carole e VAN ESTERIK, Penny. Food and Culture: a reader. New York, Routledge, 1997 [1946].

FREUD, Sigmund. Three contributions to the theory of sex. New York, Dutton, 1962.

GARFINKEL, Paul E. e GARNER, David M. Anorexia nervosa: a multidimensional perspective. New York, Brunner/ Mazel, 1982.

GEERTZ, Clifford. The interpretation of culture. Selected essays. New York, Basic Books, 1973.

GILLIGAN, Carol. In a different voice: psychological theory and women's development. Cambridge, Harvard University Press, 1981. 
Uma visão antropológica do prodigioso jejum de mulheres ocidentais

GoODY, Jack. Cooking, cuisine and class: a study in comparative sociology. New York, Cambridge University Press, 1982.

GORDON, Richard A. A sociocultural interpretation of the current epidemic of eating disorders. In: BLINDER, B. J.; Chaiting, B. F. e Goldstein, R. (eds.) The eating disorders. Great Neck, New York, PMA Publishing, 1988.

HolmBerg, Allan R. Nomads of the long bow: the Siriono of eastern Bolivia. Prospect Heights. Ill. Waveland, 1969.

HSU, L. K. George. Are eating disorders becoming more common in blacks? International Journal of Eating Disorders 6 (1), 1987, pp.113-24.

KAHN, Miriam. Always hungry, never greedy: food and the expression of gender in a Melanesian society. New York, Cambridge University Press, 1986.

KATONA-APTE, Judit. Dietary aspects of acculturation in South Asia. In: ARNOTT, Margaret L. Gastronomy: the anthropology of food habits. The Hague, Mouton, 1975.

LAWRENCE, Marilyn. The anorexic experience. London, Women's Press, 1984.

LEE, Richard B. The !Kung San: men, women and work in foraging society. New York, Cambridge University Press, 1979.

. The dobe !Kung. New York, Holt, Rinehart \& Winston, 1984.

LEVENKRON, Steven. The best little girl in the world. New York, Warner, 1978.

LÉVI-STRAUSS, Claude. The elementary structures of kinship. Boston, Beacon, 1967.

. The raw and the cooked: introduction to a science of mythology. New York, Harper \& Row, 1969.

LIU, Aimee. Solitaire. New York, Harper \& Row, 1979.

MACKENZIE, Margaret. Self-control, moral responsability, competence and rationality: obesity as failure in american culture. Obesity/Bariatric Medicine 5 (4), 1976, pp.132-33.

MACLEOD, Sheila. The art of starvation: a story of anorexia and survival. New York, Schocken, 1981. 
MALINOWSKI, Bronislaw. Argonauts of the western pacific. New York, Dutton, 1922.

MARSHALl, Lorna. The !kung of Nyae Nyae. Cambridge, Harvard University Press, 1976.

MAUSS, Marcel. The gift: forms and functions of xxchange in archaic societies. New York, Norton, 1967 [1925].

MEAD, Margaret. Male and female: a study of the sexes in a changing world. New York, Morrow, 1967.

MEIGS, Anna. Food, sex and pollution: a New Guinea religion. New Brunswick-NJ, Rutgers University Press, 1984.

MESSER, Ellen. Small but healthy? Some cultural considerations. Human Organization 48 (1), 1989, pp.39-52.

MESSINA, Maria. The odour of piety. Paper presented at the 87th Annual Meeting of the Amercian Anthropological Association, 1988.

MINUCHIN, Salvador; RosmAn, Bernice L. e BAKER, Lester. Psychosomatic falimies: anorexia nervosa in context. Cambridge, Harvard University Press, 1978.

MuRPHY, Yolanda e MuRPHY, Robert F. Women of the Forest. New York, Columbia Unviersity Press, 1985.

NoCHLIN, Linda. Women, art, and power and other essays. New York, Harper \& Row, 1988.

ORBACH, Susie. Fat is a feminist issue: the anti-diet guide to permanent weight loss. New York, Berkeley Books, 1978.

. Fat is a feminist issue, II: a program to conquer compulsive eating. New York, Bekeley, 1982.

Palazzoli, Maria Selvini. Self-starvation: from the intrapsychic to the transpersonal approach to anorexia nervosa. London, Chaucer, 1974.

PANDIAN, Jacob. Anthropology and the western tradition: toward an authentic anthropology. Prospect Heights, III, Waveland, 1985. 
Uma visão antropológica do prodigioso jejum de mulheres ocidentais

PARKER, Sheila et alii. Body, image and weight concerns among African American and White adolescent females: differences that make a difference. Human Organization 54 (2), 1995, pp.103-114.

PAUL, Lois. The mastery of work and the mistery of sex in a Guatemalan Village. In: ROSALDO, Michelle Zimbalissst and LAMPHERE, Louise. (eds.) Women, culture and society. Stanford, Stanford University Press, 1974.

PEACOCK, James L. The anthropological lens: harsh light, soft focus. New York, Cambridge University Press, 1986.

POWDERMAKER, Hortense. An anthropological approach to the problem of obesity. Bulletin of the New York Academy of Medicine 36, 1960, pp.286-295.

RICHARDS, Audrey. Land, labour and diet in Norhern Rhodesia: an economic study of the Bemba Tribe. Oxford, Oxford University Press, 1939.

SAHLINS, Marshall. Stone age economics. Hawthorne-N.Y., Aldine, 1972.

SCHWARTZ, Hillel. Never satisfied: a cultural history of diets, fantasies and fat. New York, Free Press, 1986.

SHACK, Dorothy N. Nutritional processes and personality development among the gurage of Ethiopia. Ethnology 8 (3), 1969, pp.292-300. Reimpresso em: COUNIHAN, Carole e VAN ESTERIK, Penny. Food and Culture: a reader. New York, Routledge, 1997.

SHACK, William A. Hunger, anxiety and ritual: deprivation and spirit possession among the gurage of Ethiopia. Man 6(1), 1971, pp.30-45. Reimpresso em: COUNIHAN, Carole e VAN ESTERIK, Penny. Food and Culture: a reader. New York, Routledge, 1997.

SHOSTAK, Marjorie. Nisa, the life and words of a !kung woman. New York, vintage, 1981.

SISKIND, Janet. To hunt in the morning. New York, Oxford, 1973.

STACK, Carol B. All our kin: strategies for survival in a black community. New York, Harper \& Row, 1974. 
StRIEGEL-MoORE, Ruth H.; SilbersteIn, Lisa R. e Rodin, Judith. Toward an understanding of the risk factors for bulimia. American Psychologist 41(3), 1986, pp.246-263.

STYLES, Marvalene H. Soul, Black women and food. In: Kaplan, J.R. (ed.) A woman's conflict, the special relationship between women and food. Englewood Cliffs NJ, Prentice-Hall, 1980.

TAGGART, James M. Nahuat myth and social structure. Austin, University of Texas Press, 1983.

TAMBIAH, S. J. Animals are good to think and good to prohibit. Ethnology 8(4), 1969, pp.423-459.

THOMAS, Elizabeth M. The harmless people. New York, Knopf, 1959.

THOMPSON, Becky W. A hunger so wide and so deep: American women speak out on eating problems. Minneapolis, University of Minnesota Press, 1994.

TURNBULL, Colin M. The mountain people. New York, Simon \& Schuster, 1972.

TYLOR, Sir Edward Burnett. Primitive culture, vol. 1. New York, Harper \& Row, 1958 [1871].

VERDIER, Yvonne. Pour une ethnologie culinaire. L'Homme 9(1), 1969, pp.49-57.

WeINER, Annette. The trobrianders of Papua New Guinea. New York, Holt, Rinehart \& Winston, 1988.

WeInSMANTEL, M. J. Food, gender and poverty in the Ecuadorian Andes. Philadelphia, University of Pennsylvania Press, 1988.

WINNICK, Myron. Hunger disease: studies by the Jewish Physicians in the Warsaw Ghetto. New York, Wiley, 1979.

Wolf, Eric. Anthropology. New York, Norton, 1974.

YOUNG, Michael W. "The worst disease": the cultural definition of hungers in Kalauna. In: Manderson, Lenore. (ed.) Shared wealth and symbol: food, culture and society in Oceania and Southeast Asia. New York, Cambridge University Press, 1986. 